\title{
A rare cause of duodenal stricture
}

\author{
Hossam Al-Hilou, Nicholas Carroll, Asif Jah, Susan Davies, Miles Parkes
}

Addenbrooke's hospital, Cambridge, UK

Correspondence to Hossam Al-Hilou, hal-hilou@doctors.org.uk

\section{Summary}

The authors report the case of a 62-year-old lady who had never lived overseas and who presented with symptoms of gastric outflow obstruction with weight loss. Endoscopic investigation demonstrated a tight, impassable stricture in the second part of the duodenum, with CT demonstrating a mass and surrounding lymphadenopathy. Extrinsic compression at this site in UK residents in late middle age usually heralds a diagnosis of pancreatic malignancy. In this case, investigation by endoscopic ultrasound with sampling of an otherwise inaccessible lymph node to obtain 'micro biopsies' by fine needle aspiration allowed a diagnosis of duodenal tuberculosis. The patient has responded to appropriate antibiotic therapy and is now well.

\section{BACKGROUND}

Our case illustrates duodenal tuberculosis (TB), which is a rare manifestation of $\mathrm{TB}$ enteritis especially with the lack of pulmonary involvement in a patient from a lowrisk population demographic. Conventional radiologic and endoscopic biopsy findings are often non-specific, and surgery is often required for diagnosis.

Endoscopic ultrasound (EUS) has become an important tool in the armamentarium of gastroenterologists for the diagnosis of gastrointestinal (GI) lesions. The specificity and sensitivity of EUS is enhanced with fine needle aspiration (FNA) micro biopsies. This is designed to generate cytological samples, with adjuncts such as flow cytometry for clonality being helpful in the assessment of lymphomas. However, tissue micro biopsies are frequently obtained, which can be processed for histological analysis, including special stains. Our case illustrates the benefits of this technique.

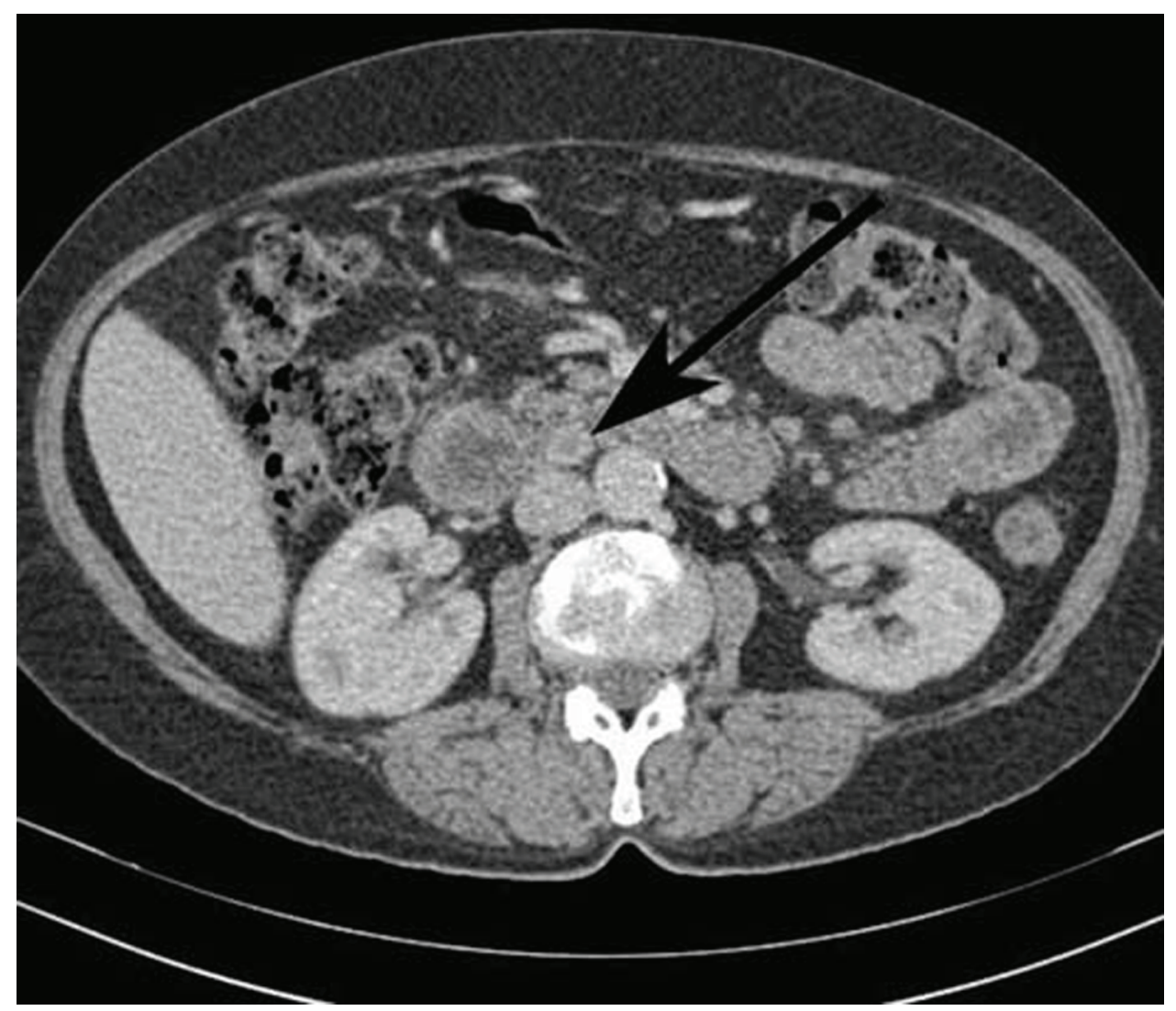

Figure 1 CT scan with abnormal area arrowed. 


\section{BMJ Case Reports}

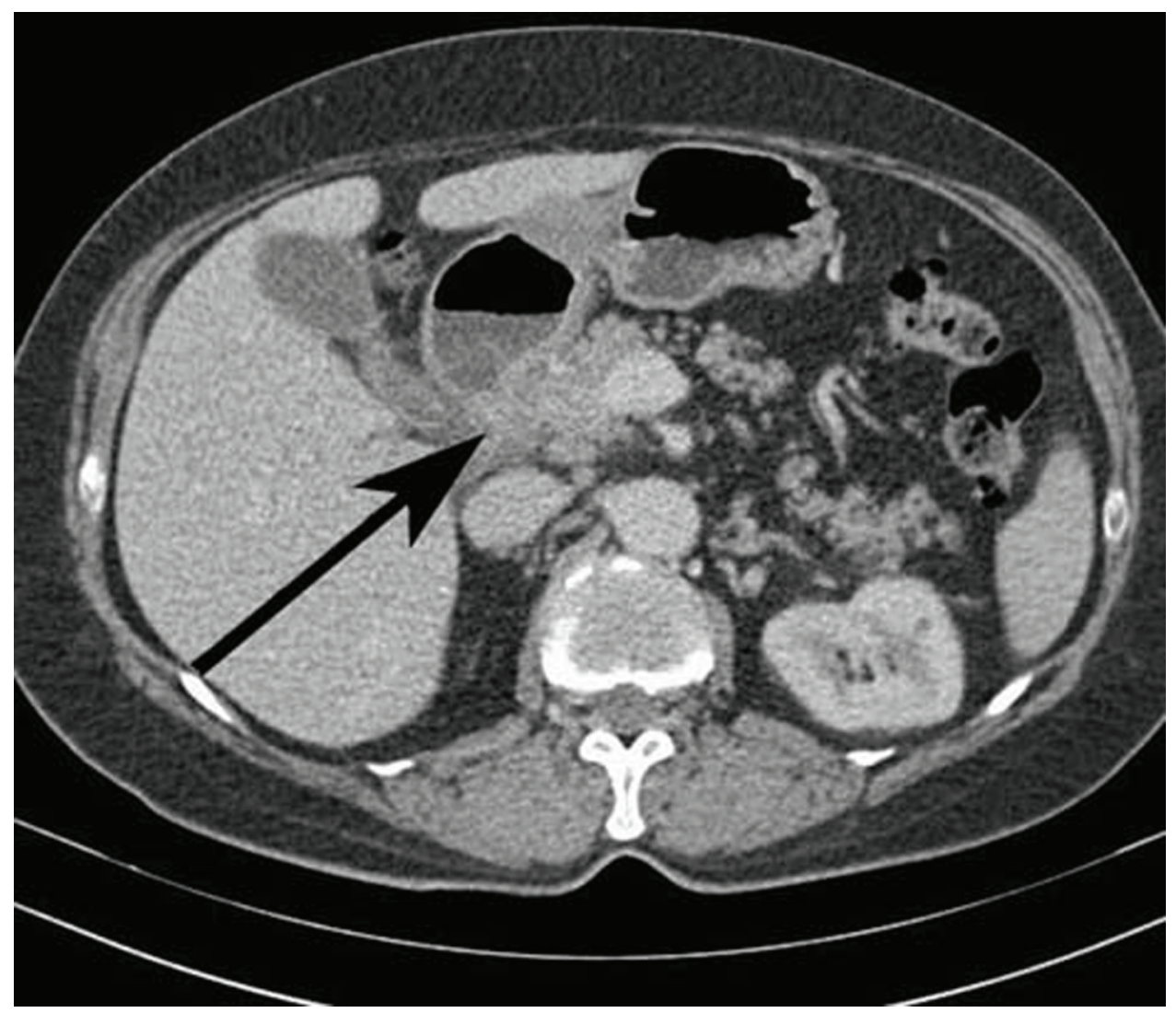

Figure 2 Abdominal CT scan showing diffuse soft tissue density between D2 and the porta hepatis.

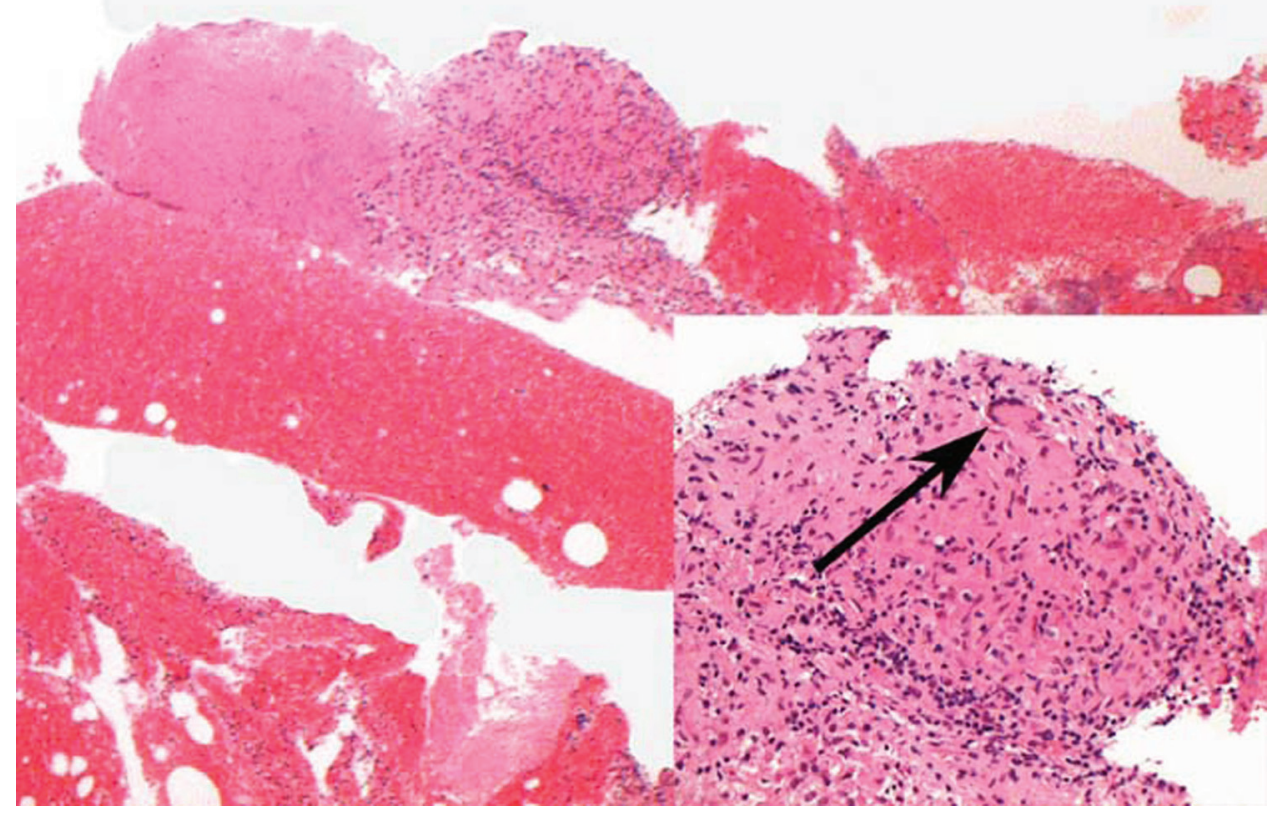

Figure 3 Multiple small tissue fragments with blood clot. Inset high power view showing epithelioid histiocytes, some lymphocytes and one giant cell (arrowed). Necrosis was also evident. 


\section{BMJ Case Reports}

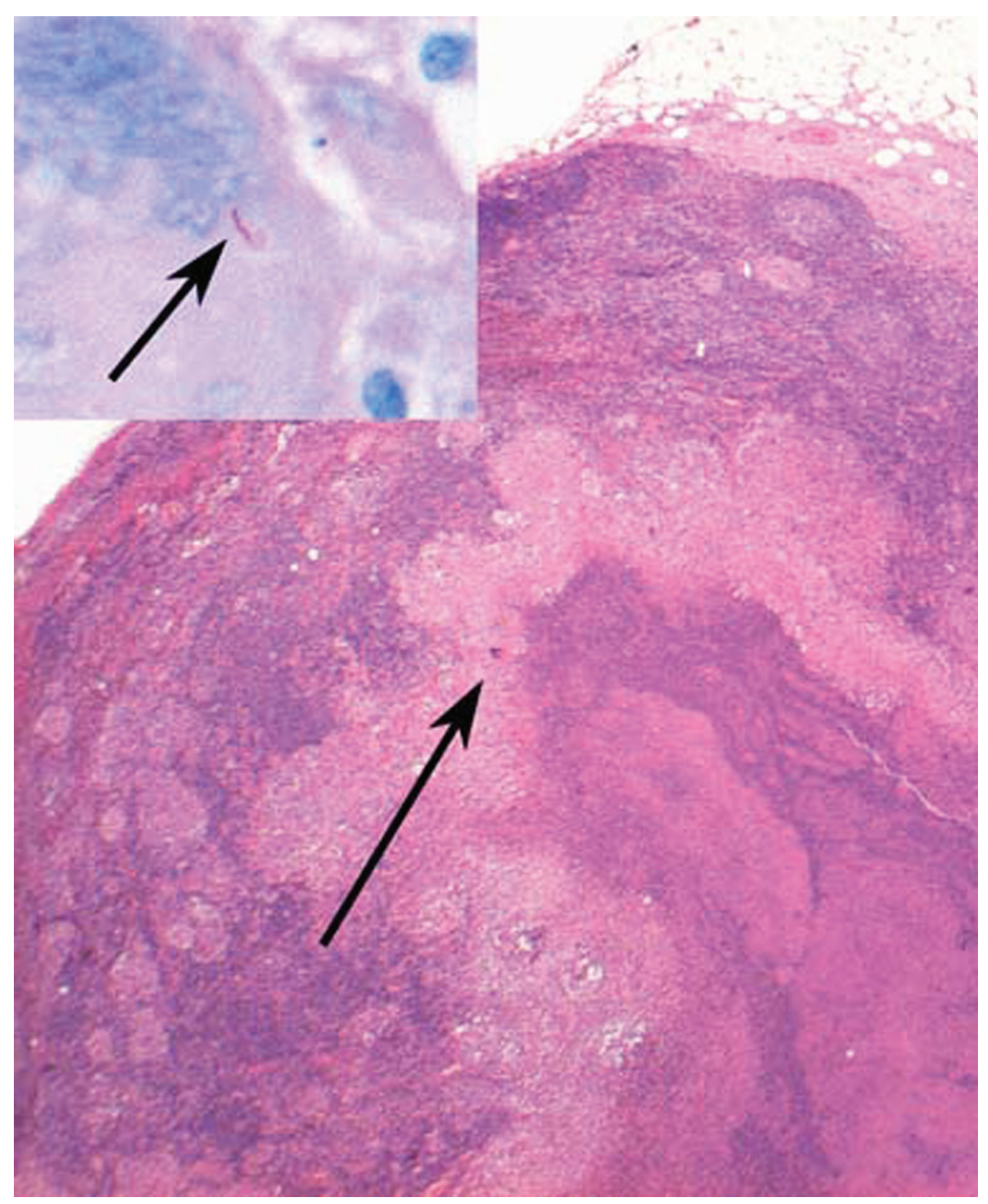

Figure 4 Low power view of lymph node: Langhan's type giant cell (arrow) amid a rim of coalesced pale granulomata, which themselves surround a large area of necrosis. Inset: Multiple 7- $\mu$ m-thick sections from the surgical resection sample were stained by Ziehl-Nielson technique. A single AAFB (acid and alcohol fast bacillus) was identified (arrowed), which is diagnostic for Mycobacterium tuberculosis.

\section{CASE PRESENTATION}

A 62-year-old lady was referred on the '2-week cancer pathway' with a 9-month history of heartburn and chest discomfort exacerbated by eating, malaise and a mild microcytic anaemia (haemoglobin $10.5 \mathrm{~g} / \mathrm{dl}$, MCV $74 \mathrm{fl}$ ). Her chest discomfort had initially improved with proprietary antacids and omeprazole. With time, however, her symptoms had become more resistant and as a consequence she had lost her appetite and $4 \mathrm{~kg}$ of weight.

The patient was a Caucasian semiretired care worker, a non-smoker and a very occasional alcohol consumer. Her medical history included an appendicectomy, caesarean section and osteoporosis. Medication at presentation included omeprazole, alendronate, calcium and iron supplementation.
Examination was entirely unremarkable, including cardiovascular, respiratory and abdominal systems.

\section{INVESTIGATIONS}

Blood investigations revealed normal liver function tests, urea and electrolytes, creatinine, $\mathrm{C}$ reactive protein, lactate dehydrogenase, serum angiotensin-converting enzyme and negative tumour markers, including chromogranin $\mathrm{A}$ and $\mathrm{B}$.

Gastroscopy showed large gastric residue and a tight stricture in the second part of the duodenum. Subsequently, a CT abdomen/pelvis was undertaken (figure 1), showing enlarged heterogeneous mesenteric lymph nodes around D2 and an adjacent mass (figure 1,2). 


\section{BMJ Case Reports}

The tissue sample was obtained by EUS with FNA of the lymph nodes arrowed in figure 1. The 'micro biopsies' that can be obtained using this technique are amenable to histological examination, not just cytology. The microscopic features are shown in (figure 3).

The likely diagnosis was felt to be TB, but with the differential including granulomatous response to malignancy, we felt further lymph node sampling was necessary. This required laparotomy due to the retroperitoneal location of the nodes. The diagnosis was confirmed histologically (figure 4) and on culture, which revealed Mycobacterium tuberculosis.

The diagnosis is duodenal stricture with lymphadenopathy secondary to $M$ tuberculosis.

\section{DIFFERENTIAL DIAGNOSIS \\ - Malignancy \\ - Crohn's disease}

\section{TREATMENT}

She was treated with oral nutritional support and anti-TB therapy (rifater, ethambutol and pyridoxine).

\section{OUTCOME AND FOLLOW-UP}

Following diagnosis her symptoms have settled with nutritional support and anti-TB therapy (rifater, ethambutol and pyridoxine) - without need for endoscopic dilatation or operative intervention.

The patient had always lived in the UK and never travelled outside Europe. However, in retrospect, it turned out that as an infant she had for 2 years lived with an aunt who had been treated for TB in a sanatorium some years previously.

\section{DISCUSSION}

TB remains one of the deadliest infectious diseases worldwide. There were an estimated 8.8 million new TB cases and 1.6 million TB-related deaths in $2005 .{ }^{1}$ The UK Health Protection Agency reported 9153 cases in the UK in 2009, mostly in people born outside the UK. The GI tract is the sixth most common extra pulmonary site. ${ }^{2} \mathrm{~TB}$ of the GI tract most often affects the ileocaecal region. ${ }^{3}{ }^{4}$ Duodenal involvement accounts for only $2.3 \%$ of tuberculous enteritis. ${ }^{3}$ Duodenal involvement manifests either as intrinsic ulceration and stricture formation or extrinsic compression by enlarged tuberculous lymph nodes. ${ }^{5}$ The clinical manifestations of duodenal TB are varied and non-specific. Commonly, duodenal TB may present with dyspepsia or duodenal obstruction.

Radiologic findings and endoscopic biopsy are often non-specific, thus many patients need surgical intervention for diagnosis. ${ }^{67}$ Although the histological findings following EUS and FNA were strongly suggestive of TB in our case, the multi-disciplinary team deemed it prudent to proceed to surgery to obtain histological and microbiological confirmation. An alternative approach, which would have avoided the need for laparotomy, would have been to commence antituberculous therapy and monitor treatment to response.

Once a diagnosis is made, a combined therapeutic strategy should begin with antibiotic therapy and nutritional support. The recommended treatment for GI, hepatic and pancreatic TB is conventional antituberculous therapy for a minimum of 6 months. ${ }^{8}$ Associated intestinal strictures often improve with antituberculous therapy, although endoscopic dilatation or operative intervention may be required for persisting obstructive symptoms.

Learning points

TB enteritis should be considered as a possible differential diagnosis even in the absence of overt risk factors.

- Radiological, endoscopic and surgical findings in TB enteritis can be non-specific. Definitive diagnosis requires tissue sampling for histology and culture.

- Our case illustrates the benefits of EUS FNA as it offers the only means of sampling retroperitoneal lymph nodes besides laparotomy.

- All patients diagnosed with TB enteritis should receive antitubercular chemotherapy; surgery may be required for complications.

- Not all dyspeptic patients with 'red flag' signs have cancer, but a gastroenterology opinion for diagnostic work-up can still be helpful even once malignancy has been excluded.

\section{Competing interests None.}

Patient consent Obtained.

\section{REFERENCES}

1. World Health Organisation. Global Tuberculosis Control: Surveillance, Planning, Financing. Geneva, Switzerland: World Health Organisation, 2007.

2. Marshall JB. Tuberculosis of the gastrointestinal tract and peritoneum. $A m \mathrm{~J}$ Gastroenterol 1993;88:989-99.

3. Padussis $\mathbf{J}$, Loffredo B, McAneny D. Minimally invasive management of obstructive gastroduodenal tuberculosis. Am Surg 2005;71:698-700.

4. Vijayraghavan M, Arunabh Sarda AK, et al. Duodenal tuberculosis: a review of the clinicopathologic features and management of twelve cases. Jpn J Surg 1990;20:526-9.

5. Gupta SK, Jain AK, Gupta JP, et al. Duodenal tuberculosis. Clin Radiol 1988;39:159-61.

6. Dargan P, Sinha SK, Singh N, et al. Gastroduodenal tuberculosis: a report of three cases and review of literature. Internet J Gastroenterol 2005;4

7. Negi SS, Sachdev AK, Chaudhary A, et al. Surgical management of obstructive gastroduodenal tuberculosis. Trop Gastroenterol 2003;24:39-41.

8. Blumberg HM, Leonard MK Jr, Jasmer RM. Update on the treatment of tuberculosis and latent tuberculosis infection. JAMA 2005;293:2776-84. 


\section{BMJ Case Reports}

This pdf has been created automatically from the final edited text and images.

Copyright 2011 BMJ Publishing Group. All rights reserved. For permission to reuse any of this content visit http://group.bmj.com/group/rights-licensing/permissions.

BMJ Case Report Fellows may re-use this article for personal use and teaching without any further permission.

Please cite this article as follows (you will need to access the article online to obtain the date of publication).

Al-Hilou H, Carroll N, Jah A, Davies S, Parkes M. A rare cause of duodenal stricture. BMJ Case Reports 2011;10.1136/bcr.10.2010.3379, date of publication

Become a Fellow of BMJ Case Reports today and you can:

- Submit as many cases as you like

- Enjoy fast sympathetic peer review and rapid publication of accepted articles

- Access all the published articles

- Re-use any of the published material for personal use and teaching without further permission

For information on Institutional Fellowships contact consortiasales@bmjgroup.com

Visit casereports.bmj.com for more articles like this and to become a Fellow 